\title{
As AÇões Individuais Para o Fornecimento de Medicamentos no ÂMbito do SUS: Características dos Conflitos e Limites para a A tuação Judicial
}

\author{
LEGAL SUITS CONCERNING SUPPLY OF MEDICINES IN THE BRAZILIAN \\ PUBLIC HEALTH SYSTEM: CHARACTERISTICS AND LIMITS FOR THE \\ JUDICIAL PERFORMANCE
}

Danielle da Costa Leite Borges ${ }^{(*)}$ Maria Alicia Dominguez, Ugáa $\hat{a}^{(* *)}$

\section{RESUMO}

Tendo como ponto de partida o crescente número de ações judiciais para o fornecimento de medicamentos no âmbito do Sistema Único de Saúde (SUS), fato que recentemente vem despertando o interesse tanto na área do Direito como na da saúde pública, o presente artigo tem como objetivo discutir a atuação do Poder Judiciário nos conflitos individuais para efetivação do direito à saúde e pretende contribuir para o debate sobre a intervenção do Poder Judiciário nas políticas públicas, especialmente nas de saúde, fenômeno este denominado judicialização. Para tanto, os autores partem do conceito de judicialização proposto pela Ciência Política para analisar as características e os limites da atuação do Judiciário nos conflitos individuais para efetivação do direito à saúde e buscam, ao final, estabelecer critérios para a superação de tais limites no julgamento das ações para o fornecimento de medicamentos no âmbito do SUS.

\section{Palavras-chave}

Ações Judiciais; Judicialização; Medicamentos; SUS.

(*) Advogada, mestre em Saúde Pública pela Escola Nacional de Saúde Pública Sergio Arouca (ENSP/FIOCRUZ) e doutoranda do Departamento de Direito do Instituto Universitário Europeu (Florença/ltália). E-mail:<danielle.borges@superig.com.br>.

${ }^{(* *}$ Pesquisadora Titular do Departamento de Administração e Planejamento em Saúde, da ENSP/ FIOCRUZ. E-mail:<domingue@ensp.fiocruz.br>.

Recebido em 25.6.08. Reapresentado em 30.9.08. Aprovado em 1.10.08. 


\begin{abstract}
Considering the increase of the number of lawsuits to the supply of medicines at the range of the Brazilian National Public Health System (Sistema Único de Saúde - SUS), this article has the objective of discussing the Judiciary Power performance in the judicial conflicts concerning the right to health, especially regarding its characteristics and limits. This work also aims at contributing to the debate over the intervention of the Judiciary Power on public policies, especially concerning those pertaining to health, a phenomenon called judicialization. In this direction, this paper analyzes the characteristics and limits of judicial performance in those cases and it intends to establish criteria to the overcoming of these limits on judgments concerning the supply of medicines by the state for the SUS users.
\end{abstract}

\title{
Keywords
}

Brazilian National Public Health System; Drugs; Judicialization; Lawsuits.

\section{INTRODUÇÃO}

O crescente número de ações judiciais propostas por usuários do Sistema Único de Saúde para garantir o fornecimento de medicamentos tem sido motivo de preocupação para os gestores de saúde em todos os níveis federativos. O volume de ações judiciais desse tipo vem crescendo não apenas nos Tribunais Estaduais ${ }^{(1)}$, passando a ocupar espaço também nos Tribunais Superiores do nosso país. Somente no Superior Tribunal de Justiça (STJ) os processos envolvendo o fornecimento de medicamentos passaram de 2, em 2001, para 672, em 2004(2).

Inicialmente, os medicamentos pleiteados eram basicamente aqueles para o tratamento de HIV/Aids. Após 1999, houve uma queda nos pedidos

(1) No Estado do Rio de Janeiro, o número de ações judiciais aumentou quase $350 \%$ entre 2001 e 2005. Em 2001 existiam aproximadamente 713 ações contra quase 2.500 em 2005. Dados obtidos junto à Secretaria de Estado de Saúde e Defesa Civil do Rio de Janeiro em setembro de 2006. Sobre o assunto vide BORGES, Danielle da Costa Leite. Uma análise das ações judiciais para o fornecimento de medicamentos no âmbito do SUS: o caso do Estado do Rio de Janeiro no ano de 2005. Rio de Janeiro, 2007. Dissertação (Mestrado) - Programa de Mestrado em Saúde Pública da Escola Nacional de Sáude Pública Sergio Arouca (ENSP)/FIOCRUZ. Disponível em: <http:// bvssp.cict.fiocruz.br/lildbi/docsonline/3/3/1233-borgesdclm.pdf>. Acesso em: 26 maio 2008.

(2) CONSTANTINO, Luciana; FREITAS, Silvana. Saúde em xeque. Folha de S. Paulo, 01 ago. 2005. Disponível em: <http://sistemas.aids.gov.br/imprensa/Noticias.asp?NOTCod=66473>. Acesso em: 19 jun. 2008. 
desses medicamentos, surgindo outras condições patológicas dominantes, tais como hepatite $\mathrm{C}$, hipertensão, artrite reumatoide e diabetes, situação que se mantém até hoje ${ }^{(3)}$.

Sob o ponto de vista dos gestores de saúde, as referidas ações significam um problema principalmente em razão dos gastos que a compra desses medicamentos representam. Nesse sentido, já em 2005 o então Ministro da Saúde estimou que as compras de medicamentos para atender às decisões federais consumiam algo em torno de $R \$ 4$ bilhões em todo o país ${ }^{(4)}$.

A atuação do Poder Judiciário nesses casos acaba interferindo na política de saúde planejada pelo Poder Executivo, pois, escolhas originalmente políticas e de competência dos gestores de saúde acabam sendo tomadas na esfera judicial, que passou a ser um novo caminho para a dispensação de medicamentos ${ }^{(5)}$.

O envolvimento do Poder Judiciário na esfera política, denominado pela doutrina de judicialização, é um fenômeno observado nas democracias contemporâneas, especialmente nos países em que este Poder realiza o controle de constitucionalidade das leis, e vem sendo estudado no Brasil desde os anos 90 .

As decisões judiciais nas ações individuais para fornecimento de medicamentos também representam uma interferência do Judiciário na política, especificamente na política de saúde. Contudo, essa forma de intervenção é diferente daquela comumente estudada. As referidas decisões judiciais representam um novo formato de judicialização, no qual o Poder Judiciário se substitui ao Executivo na escolha de fornecer este ou aquele medicamento, neste caso sob o fundamento de assegurar a efetivação do direito à saúde.

O Brasil fez a opção por um sistema de saúde público e universal. Apesar desta opção não significar que todos os serviços, tratamentos e medicamentos devam ser oferecidos pelo sistema, até porque os recursos disponíveis não viabilizariam esta situação, o legislador constitucional, ao tratar do direito à saúde, elaborou dispositivos amplos, deixando para a legislação infraconstitucional a regulamentação da matéria. Caberia ao legislador ordinário, portanto, definir os limites para o Estado do dever constitucional da prestação dos serviços da saúde. Todavia, até o momento não existem leis

(3) MESSEDER, Ana Márcia; OSÓRIO-DE-CASTRO, SERPA, Claudia Garcia; LUIZA, Vera Lucia. Mandados judiciais como ferramentas para garantia do acesso a medicamentos no setor público: A experiência do Estado do Rio de Janeiro, Brasil. Cadernos de Saúde Pública, Rio de Janeiro, v. 21, n. 2, p. 525-534, mar./abr. 2005.

(4) Declaração do Ministro da Saúde divulgada em matéria da jornalista Lydia Medeiros, publicada no Primeiro Caderno, Editoria O País, do jornal O Globo, de 14 mar. 2006, p. 12.

(5) Vide matéria de AMATO NETO, Vicente; PASTERNAK, Jacyr. Sistemas de atendimento à saúde. Folha de S. Paulo, dia 11 jul. 2007. Disponível em: <http://si.knowtec.com:8080/scripts-si/ MostraNoticia? \&idnoticia $=430175 \&$ idcontato $=1078$ \&origem $=$ fiqueatento \&nomeCliente $=$ PROBRASI L\&data=2007-07-11>. Acesso em: 19 jun. 2008. 
federais que disponham especificamente até onde vai o dever do Estado na esfera da saúde, especialmente no que se refere ao fornecimento de medicamentos $^{(6)}$. Na verdade, atualmente, esta regulamentação consiste em normas técnicas emanadas do Poder Executivo, mas, hierarquicamente inferiores às leis federais. São estas normas, portanto, que atualmente definem os tipos de serviço de saúde e as condições de sua prestação no âmbito do SUS, incluindo-se aí a assistência farmacêutica.

A questão é complexa não somente porque envolve diversos atores-gestores do SUS, magistrados, profissionais de saúde e cidadãos, mas, porque o tema medicamentos não está relacionado apenas a decisões sobre políticas de saúde, como também, a decisões técnicas relativas à incorporação de tecnologia. Nesse sentido, o Judiciário não só estaria intervindo na política de saúde, mas também decidindo sem o necessário conhecimento técnico.

Por este motivo, é de suma importância que o Poder Judiciário, ao se deparar com ações judiciais referentes a medicamentos, esteja ciente dos aspectos envolvendo a matéria, tais como a padronização do produto pelo Ministério da Saúde e a efetiva necessidade de uso daquele item pelo paciente.

Assim, a importância dessa investigação se justifica não apenas pela questão orçamentária, que as ações judiciais podem gerar para o sistema de saúde em todas as suas esferas, como já vem sendo noticiado por gestores de saúde, mas também para uma melhor compreensão pelo Judiciário de um tema que envolve conflitos diversos daqueles aos quais ele está acostumado a lidar e que recentemente lhe está sendo posto como uma questão urgente e da qual não poderá se abster de decidir.

Desta forma, este artigo objetiva discutir o fenômeno da judicialização decorrente da atuação do Poder Judiciário nos conflitos individuais envolvendo o direito à saúde, especificamente aqueles para o fornecimento de medicamentos, tomando-se como ponto de partida para esta análise conceitos trazidos da Ciência Política, bem como as características e os limites da atuação do Judiciário no julgamento desse tipo de conflito.

\section{A JUDICIALIZAÇÃO E AS AÇÕES INDIVIDUAIS PARA O FORNECIMENTO DE MEDICAMENTOS}

A análise da atuação do Poder Judiciário nas ações versando sobre o fornecimento de medicamentos nos remete necessariamente a um tema que

(6) As Leis ns. 8.080/90 e 8.142/90 regulamentam alguns aspectos na área da saúde, mas não tratam especificamente dos limites da prestação dos serviços de saúde pelo Estado, como é o fornecimento de medicamentos. No entanto, atualmente estão em trâmite dois projetos de lei de iniciativa do Senado Federal (Projetos de Lei do Senado n. 219/2007 e n. 338/2007) visando regulamentar a assistência farmacêutica no SUS. Ambos propõem alterações na Lei n. 8.080/90 no sentido de estabelecer limites para o fornecimento de medicamentos no âmbito do SUS. 
vem sendo muito discutido nos últimos tempos pela Ciência Política e, mais recentemente, pelo Direito, chamado judicialização. Em termos genéricos, podemos considerar a judicialização como o fenômeno constituído pela influência do Poder Judiciário nas instituições políticas e sociais. No Brasil, o tema passou a ser estudado, basicamente, após a promulgação da Constituição Federal de 1988 e sob a influência da obra coordenada por Neal Tate e Torbjörn Vallinder ${ }^{(7)}$, denominada The Global Expansion of Judicial Power. A obra, além de conceituar o que vem a ser a judicialização da política, faz uma análise das causas e condições para a ocorrência deste fenômeno, além de uma análise empírica comparada da expansão do Poder Judiciário em diversos países de diferentes continentes.

Se levarmos em consideração apenas o uso do termo judicialização iremos nos deparar com uma série de significados. Conforme apontam Maciel \& Koerner(8), "a expressão ganhou o debate público, e com isso, multiplicaram-se os seus usos e sentidos, tornados às vezes contraditórios". Estes autores fazem uma breve análise dos vários usos e sentidos do termo, desde normativo, que é o mais comum, até a utilização da expressão no sentido de processo político e social. Do ponto de vista normativo, a expressão é utilizada, por exemplo, para se referir à obrigação legal de que um determinado tema seja apreciado judicialmente, ou ainda, para indicar a preferência pela utilização da via judicial para a resolução de determinada causa. No sentido de processo político e social, a expressão é utilizada para indicar, por exemplo, a expansão do âmbito qualitativo de atuação do sistema judicial ou o simples aumento do número de processos nos tribunais.

Entretanto, apesar dos inúmeros sentidos dados à expressão judicialização, o termo ganha um conceito mais uniforme quando se refere especificamente à judicialização da política. Neal Tate e Torbjörn Vallinder consideram que a judicialização da política e a politização da justiça seriam expressões correlatas que indicariam os efeitos da expansão do Poder Judiciário no processo decisório das democracias contemporâneas.

Segundo Torbjörn Vallinder, que conceituou a expressão, a judicialização da política pode se dar de várias formas, mas o autor aponta as duas mais notáveis. A primeira - e mais comum - resultaria da atuação dos tribunais por meio da revisão judicial dos atos do Legislativo e do Executivo, baseada na Constituição e nos mecanismos de checks and balances, representando uma expansão do poder dos tribunais ou dos juízes em detrimento da esfera política ou administrativa. A segunda se daria através da introdução ou expansão dos métodos de tomada de decisão utilizados pelos tribunais

(7) TATE, C. Neal. Why the expansion of Judicial Power. In: TATE, C. Neal; VALLINDER, Torbjörn. The global expansion of Judicial Power. New York: New York University Press, 1995.

(8) MACIEL, Débora Alves; KOERNER Andrei. Sentidos da judicialização da política: duas análises. Lua Nova - Revista de Cultura e Política/CEDEC. São Paulo, n. 57, p. 115, 2002. 
para fora da esfera propriamente judicial. Resumidamente, pode-se dizer que a judicialização da política indica a expansão do poder judicial e decorre da relação inevitável entre direito e política. Nas palavras de Torbjörn Vallinder.

Thus the judicialization of politics should normally mean either (1) the expansion of the province of the courts or the judges at the expense of the politicians and/or the administrators, that is, the transfer of decision-making rights from de legislature, the cabinet, or the civil service to the courts or, at least, (2) the spread of judicial decision-making methods outside the judicial province proper. ${ }^{(9)(10)}$

A primeira forma de judicialização da política, que resultaria do poder de revisão dos atos legislativos e administrativos pelos tribunais, é chamada pelo referido autor de judicialização from without e na sua opinião teria como característica o posicionamento da esfera judicial acima das esferas legislativa e administrativa e teria como objetivo o controle da ação do Legislativo e a proteção da sociedade contra o abuso de Poder do Executivo(11).

Para clarificar o significado desse tipo de judicialização, podemos utilizar a síntese de Neal Tate, que conceitua o fenômeno como "the process by which courts and judges come to make or increasinly to dominate the making of public policies that had previously been made (or, it is widely believed, ought to be made) by other governmental agencies, especially legislatures and executives (...)"(12)(13).

Já a segunda, caracterizada pela utilização de procedimentos tipicamente judiciais pelo Executivo e Legislativo, do qual são exemplos os tribunais ou juízes administrativos e as Comissões Parlamentares de Inquérito, é chamada por Torbjörn Vallinder de judicialização from within e, nas suas palavras, significa "the introduction or expansion of judicial staff or judicial working methods in the administrative sector. Here one example can be found in the development within the administrative tribunals in Britain"(14)(15).

(9) VALLINDER, Torbjörn. When courts go marching. In: TATE, C. Neal; VALLINDER, Torbjörn. The global expansion of Judicial Power. New York: New York University Press, 1995. p. 13.

(10) Assim a judicialização da política normalmente significa tanto (1) a expansão da atuação dos tribunais ou dos juízes em detrimento da esfera política elou administrativa, isto é, a transferência do poder de decisão do legislativo, do gabinete ou da casa civil para os tribunais; ou, ainda, (2) a expansão dos métodos de decisão usados pelo judiciário para fora da esfera de atuação dos tribunais. Tradução livre das autoras.

(11) VALLINDER, Torbjörn. op. cit., p. 15.

(12) TATE, C. Nea. I., op. cit., p. 28.

(13) O processo pelo qual os tribunais e os juízes decidem ou controlam as políticas públicas previamente estabelecidas pelas demais esferas de governo, especialmente o executivo e o legislativo. Tradução livre das autoras.

(14) VALLINDER, Torbjörn. op. cit., p. 16.

(15) A introdução ou expansão do aparato judicial ou dos métodos de decisão do judiciário na esfera administrativo. Um exemplo pode ser observado pelo desenvolvimento dos tribunais administrativos na Inglaterra. Tradução livre das autoras. 
Apesar de Torbjörn Vallider apontar dois significados para a expressão judicialização da política, este trabalho se aterá, especialmente com foco no caso brasileiro, ao tipo from without, já que aqui tratamos de decisões judiciais e tais atos estão diretamente relacionados à atuação e eventual expansão do poder dos tribunais, fenômeno estudado neste tipo de judicialização.

No Brasil, alguns autores já estudaram o fenômeno, entre eles destacam-se Ariosto Teixeira ${ }^{(16)}$ e Marcos Faro de Castro(17), sendo certo que seus estudos constituem pesquisas empíricas acerca das ações de inconstitucionalidade propostas perante o Supremo Tribunal Federal. Outra grande contribuição sobre o assunto foi dada por Werneck Vianna et al., com o trabalho A judicialização da política e das relações sociais no Brasil( ${ }^{(18)}$. Nela, os autores estudaram a judicialização no Brasil a partir das transformações constitucionais ocorridas com a promulgação da Constituição de 1988, que ampliou os instrumentos de proteção judicial, permitindo um maior protagonismo dos tribunais, que passaram a ser utilizados por minorias parlamentares, governos estaduais e associações civis e profissionais.

A judicialização da política no Brasil é estudada por Werneck Vianna et al. com base no conceito de judicialização from without de Torbjörn Vallinder, ou seja, a partir da ideia de revisão judicial das decisões do Executivo e do Legislativo. Já a judicialização das relações sociais é estudada a partir da ideia de acesso à justiça. É interessante notar que os mencionados autores, ao estudarem o caso brasileiro, também fazem uma análise das causas que, em suas opiniões, implicaram "uma crescente institucionalização do direito na vida social, invadindo espaços até então inacessíveis a ele, como certas dimensões da esfera privada"(19).

Nesse sentido, citam como exemplo o surgimento do Direito do Trabalho, nascido dos êxitos do movimento operário, que veio a conferir um caráter público a relações da esfera privada, como o contrato de compra e venda do trabalho. Além disso, também destacam o surgimento do Estado de Bem-Estar Social e a positivação dos direitos fundamentais como causas favorecedoras. Expõem ainda uma última causa que teria favorecido a interferência do Judiciário, não propriamente na política, mas sim na sociedade de um modo geral, que seria a emergência de conflitos coletivos em torno da produção, do consumo e da distribuição de bens, surgidos no contexto da globalização. Segundo os autores, tais conflitos têm sido objeto de tutela jurídica

(16) TEIXEIRA, Ariosto. A judicialização da política no Brasil (1990-1996). Dissertação (Mestrado) — Universidade de Brasília - UnB, Brasília, 1997. Mimeo.

(17) CASTRO, Marcos Faro de. O Supremo Tribunal Federal e a judicialização da política. Revista Brasileira de Ciências Sociais, São Paulo, v. 12, n. 34, jul. 1997.

(18) VIANNA, Luiz Jorge Werneck et al. A judicialização da política e das relações sociais no Brasil. Rio de Janeiro: Revan, 1999.

(19) Id. Ibid., p. 15. 
por meio de inovações processuais, como é o caso da ação civil pública, resultando em um envolvimento do Direito na própria construção da sociabilidade e, a partir daí, em um novo padrão de relacionamento entre os Poderes e a conformação de um cenário para a ação social substitutiva a dos partidos e a das instituições políticas propriamente ditas, no qual o Poder Judiciário surge como uma alternativa para a resolução de conflitos coletivos, para a agregação do tecido social e mesmo para a adjudicação de cidadania.

Além disso, Werneck Vianna et al. estudaram a ocorrência da judicialização das relações sociais, correspondente à crescente invasão do Direito na vida social. O fenômeno pode ser verificado, por exemplo, na regulação pelo Direito das decisões dos pais na educação dos filhos, na legislação que regula a interação entre indivíduos de diferentes origens étnicas, da qual é exemplo a legislação brasileira que proíbe manifestações de preconceito racial, na ação de grupos que reclamam a intervenção do Direito na institucionalização da sua condição, como é o caso dos homossexuais que buscam a equiparação da união civil ao casamento.

No Brasil, esse processo teve como "divisor de águas" a criação dos Juizados Especiais Cíveis e Criminais, que teriam democratizado o acesso à justiça, passando a ser "responsáveis pela exposição do Poder Judiciário, sem qualquer tipo de mediação social ou política, às expectativas por direito e cidadania de setores socialmente emergentes"(20).

Verifica-se, portanto, que a judicialização da política no Brasil foi estudada e caracterizada por grande parte dos autores por meio da atividade de controle de constitucionalidade das leis e atos normativos federais realizada pelo Poder Judiciário, especificamente pelas ADINs propostas por atores políticos, dentre eles grupos sociais minoritários e partidos de oposição, perante o Supremo Tribunal Federal, com base na conceituação de Torbjörn Vallinder de judicialization from without. Com relação à judicialização das relações sociais, Werneck Vianna et al. conceituaram e estudaram a categoria a partir da criação dos Juizados Especiais.

No entanto, a judicialização da política pode indicar outras formas de atuação do Judiciário na arena política. Nesse sentido, além da atuação do Judiciário como controlador da atividade das instituições legislativas (controle de constitucionalidade), recentemente, o referido Poder tem emergido como arena de discussão e decisão de políticas públicas, mas com outra forma de atuação, representada pela utilização de meios processuais comuns para alterar as políticas públicas em curso. Apesar de ainda pouco estudada, essa forma de atuação do Poder Judiciário vem sendo observada especialmente no que se refere às políticas sociais, entre elas as de saúde.

(20) Id. Ibid., p. 155. 
As Ações Individuais para o Fornecimento de Medicamentos no Âmbito do SUS ... 21

Em recente monografia, intitulada $O$ Judiciário e as Políticas de Saúde no Brasil: o caso Aids, Ferreira et al. abordam esse modelo de judicialização da política e afirmam que nesses casos o Judiciário agiria como um veto player e provedor de veto points, ao qual os atores políticos recorreriam no intuito de buscar a efetivação de interesses não alcançados na arena política. Nesse sentido, expõem os autores:

(...) veto players seriam atores políticos, individuais ou coletivos, cujo consentimento seria necessário para o estabelecimento de políticas públicas. Referidos atores políticos exerceriam esse poder de veto (sobre legislação ou políticas públicas que atinjam os interesses ou objetivos políticos desses) tendo em vista arranjos institucionais, os denominados veto points. (21)

Essa nova forma de interferência do Judiciário nas políticas públicas também teve como condição favorável a emergência do sistema brasileiro de seguridade social que, com o objetivo de cumprir uma agenda igualitária, incluiu entre suas tarefas não mais apenas a racionalização e burocratização das atividades estatais, mas também, a elaboração de políticas capazes de garantir aos cidadãos saúde, educação, emprego, moradia etc.

A expansão da atividade estatal no sentido da promoção de direitos sociais tornou necessário que esse novo Estado ampliasse também sua legislação, como forma de incorporar os ideais de justiça social, nascendo, então uma ampla legislação voltada para as questões socioeconômicas, sendo o exemplo mais claro o das constituições dirigentes ${ }^{(22)}$, que incluem um extenso rol de direitos de natureza social. Portanto, de guardião das liberdades individuais (chamados classicamente de direitos negativos), o Poder Judiciário passou a ter uma tarefa mais complexa, qual seja, a de garantir a efetivação dos direitos sociais.

É nessa forma de judicialização da política que se situa o caso das ações judiciais estudadas neste artigo. Nesta situação, temos cidadãos buscando individualmente, e mediante procedimentos judiciais comuns, a efetivação de interesses relacionados ao direito social à saúde, não efetivados na esfera Executiva. Sobre a evolução desse novo formato de judicialização, destaca José Reinaldo de Lima Lopes que:

De fato, dos anos 80 para cá, assistiu-se ao recurso aos tribunais como forma de garantir a efetividade a declarações de direitos sociais. Este recurso teve dois importantes aspectos: criar uma nova forma de visibilidade para certas demandas

(21) FERREIRA, Camila Duran et al. O Judiciário e as políticas de saúde no Brasil: o caso Aids. São Paulo, 2004. Monografia vencedora do Concurso de Monografias "Prêmio IPEA 40 anos". Disponível em: <http://getinternet.ipea.gov.br/Sobrelpea/40anos/estudantes/monografiacamila.doc>. Acesso em: 12 jan. 2008.

(22) Vide CANOTILHO, José Joaquim Gomes. Constituição dirigente e vinculação do legislador. 2. ed. Coimbra: Almedina, 2001. 
e colocá-las sob a linguagem própria do direito, uma linguagem de deveres correlativos e de responsabilidades definidas. Esta nova judicialização contribui para um novo alcance da democracia entre nós. Ao colocar os temas em discussão sob a linguagem do direito dá-se um passo importante - embora ainda de resultados ambíguos - na direção de considerar os direitos sociais como direitos propriamente ditos e não como simples concessões ou benefícios dados por um paternal poder privado ou político. ${ }^{(23)}$

Como já mencionado anteriormente, por ser a saúde um bem provido pelo Estado com recursos públicos, os conflitos judiciais envolvendo este bem dizem respeito a conflitos sobre justiça distributiva, ou seja, àquela que dispõe sobre regras de apropriação individual de recursos comuns. Nesse sentido, utilizando-se a concepção aristotélica sobre justiça, encontramos, além da distributiva, a justiça comutativa ou reparadora, que está relacionada à reparação de danos. Nas palavras de Norberto Bobbio:

De uma maneira geral, adotou-se a distinção aristotélica entre Justiça distributiva e Justiça reparadora. A primeira é "aquela que se exterioriza na distribuição de honras, de bens materiais ou de qualquer outra coisa divisível entre os que participam do sistema político" (Ética, 1.930b), enquanto que a segunda está mais especificamente ligada a situações em que uma pessoa, ao receber uma ofensa de outra pessoa, pede a conseqüente reparação. ${ }^{(24)}$

Os conflitos individuais que o Poder Judiciário sempre esteve acostumado a decidir são conflitos retributivos ou bipolares, nos quais uma parte irá ganhar ou perder, devendo o julgador dizer o que é legal ou ilegal a respeito de um delito, de um contrato ou de uma indenização. Entretanto, como já se disse, atualmente, conflitos de natureza distributiva, que envolvem bens como os relacionados ao direito à saúde estão sendo levados ao Judiciário no mesmo formato daqueles sobre justiça comutativa.

A questão é que os conflitos envolvendo bens providos pelo Estado com recursos públicos não têm caráter bilateral, mas sim, caráter policêntrico ou plurilateral, já que o resultado será uma perda ou um ganho para toda a sociedade, ou seja, trata-se da alocação entre várias partes de recursos escassos ou indivisíveis e não de retribuição ou indenização entre duas partes.

Por esse motivo, os critérios e mecanismos tradicionalmente utilizados pelo Judiciário para decidir sobre conflitos bilaterais, apropriados ao exercício da justiça comutativa, não são adequados ao exercício da justiça distributiva e não deveriam ser aplicados às decisões sobre bens providos pelo Estado com recursos públicos, como aquelas sobre o direito à saúde e, em especial, sobre o fornecimento de medicamentos.

(23) LOPES, José Reinaldo de Lima. Direitos sociais: teoria e prática. São Paulo: Método, 2006. p. 165. (24) BOBBIO, Norberto. Dicionário de política. 5. ed. Brasília: Ed. da UnB; São Paulo: Imprensa Oficial do Estado de São Paulo, 2004. v. 1, p. 662. 
Muito já se estudou sobre o papel do juiz como intérprete do Direito ou também como seu criador. Num primeiro momento, entre os séculos XVIII e XIX, a atividade do juiz era tida como a de mero aplicador da lei, sem espaço para criações fora daquilo que não estivesse previsto pelo Direito. Com a expansão do papel do Poder Judiciário no século XX, o papel dos juízes se modificou, passando a se reconhecer que na interpretação do Direito está ínsito certo grau de criatividade. De acordo com esse entendimento, as lacunas existentes na lei devem ser preenchidas pelo juiz, dando margem à criação do Direito. Nesse sentido, destaca Mauro Cappelletti que o juiz

(...) reúne em si uma e outra função, mesmo no caso - que constitui, quando muito, regra não sem muitas exceções - em que seja obrigado a aplicar uma lei preexistente. Nem poderia ser de outro modo, pois a interpretação sempre implica um certo grau de discricionariedade e escolha e, portanto, de criatividade, um grau que é particularmente elevado em alguns domínios, como a justiça constitucional e a proteção judiciária de direitos sociais e interesses difusos. ${ }^{(25)}$

Recentemente, o surgimento de Constituições e legislações repletas de normas constituídas por princípios fez com que a função criativa dos juízes se mostrasse cada vez mais importante. O princípio da dignidade da pessoa humana, que norteia o ordenamento jurídico brasileiro é um exemplo claro disto (art. 1ํㅡㄹ inciso III, da Constituição Federal). Desta forma, expõe José Reinaldo de Lima Lopes que: "Saber o que exatamente diz a regra do direito constitucional, em cada caso, é uma tarefa ao mesmo tempo de aplicação da regra já existente (a constituição) e de formulação de uma nova regra, pois, em caso de dúvida, a interpretação equivale à criação da regra."(26)

Considerando-se, portanto, que os juízes exercem também uma função criativa, não sendo o juiz um mero aplicador da lei, pode-se dizer que, ao fixar o sentido e o alcance de uma determinada lei, na sua aplicação a um caso concreto, de algum modo, os juízes estão exercendo um poder normativo, não muito distante daquele existente no próprio ato de legislar.

Esse poder normativo das decisões judiciais no mundo atual, mesmo daquelas produzidas por juízes singulares, já foi estudado por inúmeros autores. Alec Stone Sweet ${ }^{(27)}$ fez uma análise sobre a resolução de conflitos na arena judicial de forma tríade, originalmente chamada Triadic Dispute Resolution - TDR, que consistiria em uma relação composta por três partes,

(25) CAPPELLETTI, Mauro. Juízes legisladores? Porto Alegre: Sérgio Fabris, 1999.

(26) LOPES, José Reinaldo de Lima. op. cit., p. 124.

(27) SWEET, Alec Stone. Governing with judges: constitutional politics in Europe. Oxford: Oxford University Press, 2000. 
formada a partir de uma disputa entre duas partes, que elegem a terceira para elidir o conflito existente. Segundo o autor, quando essa relação se forma na esfera judicial, as decisões tomadas por esta terceira parte, no caso o juiz, produzem o mesmo efeito que a lei, sendo norma para o caso concreto, já que obrigam as partes envolvidas a cumpri-la, mas também para situações abstratas, na medida em que podem servir como subsídio para outras decisões sobre o mesmo tema. Assim, nas palavras do autor:

In taking a decision and justifying it normatively, the triadic entity makes rules. First, she has made rules that are concrete, particular, and retrospective, that is, she has resolved a pre-existing dispute between two specific parties about the terms of one dyadic contract. Second, in justifying her decision - in telling us why, normatively, a given act should or should not be permitted - she has made rules of an abstract, general, and prospective nature. This is so to the extent that her decision has clarified or altered rules that comprise the normative structure. ${ }^{(28)(29)}$

Contudo, as decisões judiciais no caso de conflitos bilaterais sempre produzirão um resultado insatisfatório para uma das partes, especificamente para aquela a quem não for adjudicado o bem objeto de conflito. Entretanto, tal decisão funciona como lei entre as partes envolvidas no conflito, não podendo ser descumprida, ainda que considerada substancialmente injusta(30).

Portanto, nos conflitos bilaterais aonde estão em jogo bens particulares, a decisão por adjudicar os bens em conflito a uma das partes afetará apenas as próprias partes envolvidas na relação, ou seja, afetará um universo microjurídico. Mas, quando passamos ao caso dos conflitos plurilaterais, nos quais estão em jogo bens providos pelo Estado com recursos públicos, como é caso da saúde, a decisão sobre a adjudicação do bem afetará, ainda que indiretamente, toda a coletividade, ou um universo macrojurídico ${ }^{(31)}$.

(28) SWEET, Alec Stone. op. cit., p. 17.

(29) Ao decidir e fundamentar uma decisão com base na norma, a entidade tríade cria normas. Primeiro, ela faz normas para o caso concreto e de forma retrospectiva, ou seja, ela resolveu um conflito preeexistente entre duas partes específicas baseadas num contrato bilateral. Segundo, ao fundamentar sua decisão - ela está nos dizendo, de forma legal, porque a situação posta deve ou não ser permitida e, neste caso, ela está fazendo normas em abstrato, de forma geral e prospectivamente. É nessa medida que a decisão clarifica ou altera as leis que compõem a estrutura normativa. Tradução livre das autoras.

(30) Para melhor esclarecer os conceitos de justiça formal e justiça substancial, apropriamo-nos da lição de Norberto Bobbio para quem as ações legítimas compreendidas pela justiça formal são aquelas que se adequam a certo sistema preexistente de lei positiva e uma ação é justa quando é exigida ou permitida pelas normas deste sistema e injusta se proibida por ele. Já o conceito de justiça substancial não se baseia na conformidade da lei, mas sim na moralidade da ação. Assim, "determinadas ações não contempladas pela lei positiva, ou porventura ilegais, podem tornar-se justas. Da mesma maneira, decisões judiciais legais podem ser tidas como injustas se analisadas de um ponto de vista moral". BOBBIO, Norberto. op. cit., v. 1, p. 663.

(31) Nesse sentido, vale lembrar que distribuir ou fazer justiça distributiva é dar a cada um a sua parte no mal comum (distribuição do ônus) ou no bem comum (distribuição de benefícios). LOPES, José Reinaldo de Lima. Direitos sociais: teoria e prática. São Paulo: Método, 2006. p. 144. 


\section{LIMITES PARA A ATUAÇÃO JUDICIAL NAS AÇÕES INDIVIDUAIS PARA O FORNECIMENTO DE MEDICAMENTOS}

Assim sendo, como já se disse acima, as decisões judiciais sobre conflitos envolvendo bens providos com recursos públicos não podem seguir os mesmos critérios daquelas sobre bens privados, devendo-se levar em conta princípios da justiça distributiva. Ocorre, porém, que esses novos conflitos sobre justiça distributiva vêm crescendo rápida e significativamente, sem dar tempo para que a magistratura se aparelhe de novos critérios para o seu julgamento. Nesse sentido, expõe José Eduardo Faria que a magistratura:

Sempre esteve voltada para os processos judiciais de interesse individual oriundos de um universo microjurídico, precisa agora despertar para as "situações limite" e para os "casos difíceis", de grande interesse coletivo e com enormes repercussões no universo macrojurídico. ${ }^{(32)}$

Agora que o Judiciário se vê obrigado a dar respostas para as quais não tem experiência acumulada, precisará refletir e repensar os critérios que sempre esteve acostumado a adotar para lidar com bens de interesse privado, adaptando-se a esta outra realidade, na qual se tem bens providos pelo Estado com recursos públicos, buscando novos critérios para decidir.

Para tanto, faz-se necessário examinar quais seriam os obstáculos impostos ao Judiciário ao decidir questões relacionadas à justiça distributiva, de forma que se possa, então, pensar em novos critérios de decisão. De acordo com a análise feita por José Reinaldo de Lima Lopes ${ }^{(3)}$, seriam seis estes obstáculos ou limites.

O primeiro deles decorre dos próprios efeitos produzidos pela decisão judicial nos conflitos sobre bens comuns, tal como se coloca a saúde. Como já dito acima, nesses casos, a decisão judicial afeta eventualmente outros indivíduos que não participaram da causa e "mexer em um ponto é diretamente - e não indiretamente - mexer em todos os pontos"(34). Imagine-se, por exemplo, que um indivíduo ajuíze uma ação contra a União exigindo tratamento para transplante de fígado e o juiz responsável defira o pedido e determine o tratamento imediatamente. Este indivíduo irá "passar à frente" na fila de transplantes de outros indivíduos na mesma situação de risco; em outras palavras, a decisão judicial não afetou apenas as partes envolvidas no processo - União e indivíduo que solicitou o transplante, mas, todos os indivíduos que necessitam de transplante do órgão em questão, que podem

(32) FARIA, José Eduardo. O Judiciário e os direitos sociais: notas para uma avaliação da justiça brasileira. In: FARIA, José Eduardo (Org.). Direitos humanos, direitos sociais e justiça. 1. ed. 4. tir. São Paulo: Malheiros Ed., 2005. p. 29.

(33) LOPES, José Reinaldo de Lima. op. cit.

(34) Id. Ibid., p. 172. 
inclusive residir em outro Estado. O mesmo ocorre quando o indivíduo pleiteia judicialmente medicamentos de custo elevado que não estão padronizados pelo Estado, pois, o gasto com aquele indivíduo pode privar a coletividade de outros tratamentos de assistência à saúde.

Assim, tratar como se fosse uma questão entre duas partes, quando, na verdade, o conflito jurídico irá atingir a coletividade é um dos limites às decisões judiciais que tratam de bens comuns. Conforme bem destaca José Reinaldo de Lima Lopes, "Muitos são os problemas que não se resolvem individualmente. Por exemplo, a questão da moradia ou da saúde pública. Então o valor de determinadas decisões não pode ultrapassar determinadas pessoas, ou determinadas regiões"(35).

O segundo limite vislumbrado é a questão da legitimidade do Judiciário. Já foi mencionado acima o fato de as decisões judiciais não serem meros atos de aplicação da lei, mas, se não, a própria lei, dado o poder criativo dos juízes. $\mathrm{Na}$ verdade, a competência para fazer regras sobre distribuição e alocação de recursos, como pressupõe a justiça distributiva, é do Legislativo, cabendo sua execução ao Executivo. No entanto, o que se observa nas ações judiciais para o fornecimento de medicamentos é o Judiciário agindo na condição de legislador e administrador, pois, os juízes ao fazerem norma para o caso concreto, interpretando e aplicando o art. 196 da Constituição - determinando, consequentemente, o imediato fornecimento de medicamentos - estão interferindo diretamente na esfera de atuação do Poder Executivo. O Judiciário acaba por realizar um "julgamento sobre a opção administrativa na alocação de recursos públicos escassos ante diversas possibilidades políticas"(36).

Mesmo diante da nova estrutura de Estado surgida com o Estado de Bem-Estar Social, onde a teoria da separação de poderes deve ser interpretada de maneira mais flexível, devendo o Judiciário zelar não só pela defesa das liberdades individuais, mas também figurar como garantidor de direitos sociais previstos constitucionalmente, este Poder deve ter cautela para não alterar políticas essencialmente de competência dos demais Poderes. Como bem destaca José Reinaldo de Lima Lopes, "os tribunais não têm poderes institucionais para alocar livremente recursos orçamentários e, em caso de necessidade, não têm o poder de criar novas formas de financiamento público, constrangendo sua atuação em programas de reformas propriamente ditos"(37).

Some-se a isso uma falta de coordenação entre as esferas de governo, resultando em decisões judiciais sobre alocação de recursos e políticas

(35) LOPES, José Reinaldo de Lima. op. cit., p. 134.

(36) FERREIRA, Camila Duran et al., op. cit.

(37) LOPES, José Reinaldo de Lima. op. cit., p. 238. 
públicas sem diálogo com o órgão responsável pelo assunto - no caso da saúde, secretarias de saúde. E não se pode esquecer que, na temática da saúde, as decisões muitas vezes significam uma escolha dramática ou opção disjuntiva(38).

Como terceiro limite, e já explicitado acima, está a forma como os conflitos são levados ao Judiciário, ou seja, o contraditório bilateral. Na linha do que já foi exposto, neste modelo de controvérsia, está em disputa um bem que não pode pertencer simultaneamente a dois indivíduos, devendo haver uma divisão ou apropriação. Desta maneira, a razão jurídico-judicial e o emprego dos mecanismos tradicionalmente associados a direitos individuais protegidos judicialmente, ou o uso de categorias e lógica apropriadas ao exercício da justiça comutativa, pode resultar em decisões que produzam uma injusta distribuição de bens providos com recursos públicos, de acordo com os conceitos de justiça formal e substancial vistos acima.

Outro obstáculo vivido pelo Judiciário é sua inércia institucional. Ao contrário do Legislativo e do Executivo, aquele Poder só procede mediante provocação dos interessados, e interessados sob o ponto de vista de relações individualizadas. Quando estamos diante de decisões sobre bens comuns, como a saúde, a iniciativa de alguns pode significar, imediatamente, a lesão de outros. Nos exemplos citados anteriormente, do indivíduo que pleiteia judicialmente um tratamento de transplante ou um medicamento de alto custo, essa questão fica muito clara, já que este indivíduo que buscou o Judiciário terá o seu tratamento ou medicamento concedido, mas outros, em idêntica situação de saúde, não poderão ter acesso aos mesmos bens.

No Brasil, apesar de já se ter conseguido um avanço na questão do acesso à justiça, favorecido pela ampliação da esfera geográfica de atuação da Defensoria Pública e criação dos Juizados Especiais, sabe-se que a falta de meios e de conhecimento ainda aparece como um grande problema, gerando uma distância entre a sociedade e o Judiciário.

No caso da saúde, especificamente do fornecimento de medicamentos, a busca individual ao Poder Judiciário tem se mostrado o meio mais ágil para efetivação deste direito social, gerando um crescente número de ações judiciais. Na verdade, pode-se dizer que já existe uma expectativa por parte da sociedade de que o Judiciário solucionará questões relativas ao fornecimento de medicamentos ${ }^{(39)}$. Como destaca Alec Stone Sweet, os cidadãos litigam para obter a revisão de uma lei (de uma política pública ou prática privada) quando consideram que existem verdadeiros benefícios em levar

(38) AMARAL, Gustavo. Direito, escassez \& escolha: em busca de critérios jurídicos para lidar com a escassez de recursos e as decisões trágicas. Rio de Janeiro: Renovar, 2001. p. 181.

(39) Matéria do jornalista Antônio Marinho publicada na revista do jornal O Globo, 24 jun. 2007, p. 42. 
tais questões à esfera judicial(40). Essa busca ao Judiciário demonstra que os indivíduos provocam o Judiciário visando alterar as políticas públicas de saúde em seu benefício e, nesse aspecto, as decisões judiciais que deferem o fornecimento dos medicamentos produzem bons resultados, já que ocorre a efetivação do direito individual mediante a utilização de meios processuais comuns que terminam por alterar as políticas públicas em curso. Portanto, esse novo formato de judicialização que, conforme mencionado acima, é marcado pela utilização de meios processuais comuns para alterar as políticas públicas em curso, é impulsionado pela atuação dos indivíduos ${ }^{(41)}$.

Todavia, a solução individualizada de uma situação, que deveria ser tratada de forma coletiva - alocação de recursos e fornecimento de medicamentos - e pelos órgãos competentes, acaba por realizar justiça para o caso concreto (microjustiça), desprezando os aspectos coletivos de distribuição de recursos para a coletividade (macrojustiça).

O penúltimo obstáculo seria a tradição e a cultura do Judiciário. Este poder, diferentemente do Executivo e do Legislativo está acostumado a julgar com base em fatos passados, ou seja, em uma lei ou jurisprudência já existente. Entretanto, como as demandas sociais são dinâmicas, os conflitos distributivos necessitam de soluções voltadas para o futuro, como são as políticas públicas que definem a distribuição e alocação de recursos escassos. Sendo o fundamento das decisões judiciais sempre baseado em fatos pretéritos elas dificilmente conseguem alcançar o grau de visão a longo prazo que se precisa ter para decidir conflitos dessa natureza. Segundo José Reinaldo de Lima Lopes, "o julgador precisa nessas circunstâncias mais do que um instinto para o precedente. Ele não apenas ordena, precisa também fiscalizar e administrar. E, depois de ordenar, pode ver-se diante do problema da falta de dinheiro para cumprir sua ordem"(42).

Finalmente, o último obstáculo que se coloca para o Judiciário na solução de conflitos distributivos diz respeito ao seu aparelhamento insuficiente. Este limite, de certa maneira, se confunde com o anterior, já que para possuir uma visão voltada para o futuro, o Judiciário necessitaria estar suficientemente aparelhado ou assessorado. As soluções para conflitos sobre bens providos com recursos públicos envolvem a consulta a órgãos técnicos especializados, pesquisa estatística, dados econômicofinanceiros etc.

(40) SWEET, Alec Stone. op. cit., p. 140.

(41) Nas palavras de Alec Stone Sweet, "The delegation of conflicts to a third party is the fuel that drives judicialization. If disputes were always able to be resolved diadically, or if one of the disputants was always able to impose a solution on the other, then judicialization could not proceed". SWEET, Alec Stone. op. cit., p. 15.

(42) LOPES, José Reinaldo de Lima. op. cit., p. 214. 
Por mais que o Judiciário possa se valer de perícias especializadas, esse recurso não é suficiente para que se consiga realizar distribuição e alocação de recursos. Com relação ao tema, bem destaca Mauro Cappelletti:

Efetivamente, para a criação do direito fazem-se necessários instrumentos que não estão à disposição dos tribunais e "em muito ultrapassam o simples conhecimento do direito existente e como este se realiza". Os juízes, segundo esse entendimento, não têm possibilidade de desenvolver pessoalmente o tipo de investigações requeridas para uma obra criativa, que não podem se limitar às leis e aos precedentes, e envolvem problemas complexos e dados sociais, econômicos e políticos; não dispõem sequer dos recursos, inclusive financeiros, mediante os quais parlamentos, comissões legislativas e ministérios estão em condições de encarregar terceiros para efetuar pesquisas que, freqüentemente, nem os legisladores e administradores saberiam desenvolver por si mesmos. ${ }^{(43)}$

No caso da saúde, essa situação se torna ainda mais complicada. As decisões nesta área envolvem desde o financiamento até a alocação dos recursos e o planejamento das ações. Por isso, no campo da saúde, a utilização de regulamentos técnicos, critérios científicos, protocolos de conduta e, ainda, a necessidade de pautar-se por critérios epidemiológicos são essenciais para a definição da política de saúde, a adoção de condutas terapêuticas, a padronização de medicamentos e a incorporação de tecnologias. Nesse sentido, Lenir Santos afirma que:

Desse modo, a integralidade da assistência deverá pautar-se por regulamentos técnicos e científicos, protocolos de condutas, limites para incorporação de tecnologia, protocolos farmacológicos. A integralidade da assistência, sob esse ponto de vista, não é um conceito que admite toda e qualquer terapêutica existente ou demandada por um paciente ou profissional de saúde. Há que se ter critérios científicos e técnicos, atualizados cientificamente para embasar a incorporação desta ou daquela tecnologia, desta ou daquela terapêutica ou medicamento. ${ }^{(44)}$

Com certeza, não será o Judiciário o órgão adequado para a decisão sobre a incorporação de novas tecnologias e medicamentos, ainda mais sabendo-se que a pesquisa em Medicina está em constante progresso e que a indústria farmacêutica, por sua vez, coloca diariamente mais e mais medicamentos no mercado. Some-se a isso o poder da indústria farmacêutica em criar sua própria demanda, ofertando constantemente novos produtos que, muitas vezes, não são efetivamente inovadores e não possuem comprovação de sua eficácia ${ }^{(45)}$.

(43) CAPPELLETTI, Mauro., op. cit., p. 87.

(44) SANTOS, Lenir. SUS: contornos jurídicos da integralidade da atenção à saúde. Revista do Conselho Nacional de Secretarias Municipais de Saúde - CONASEMS, Brasília, ano 2, n. 19, p. 4647, set./out. 2006.

(45) MAGALHÃES; Sérgia Maria Starling; CARVALHO, Wania da Silva. O farmacêutico e o uso racional de medicamentos. In: ACURCIO, F. A. (Org.). Medicamentos e assistência farmacêutica. Belo Horizonte: Coopmed, 2003. p. 83-97. 


\section{CONSIDERAÇÕES FINAIS}

O cenário que se coloca com esse novo formato de judicialização indica estar ocorrendo um excesso de intervenção do Poder Judiciário no que se refere às políticas de saúde sobre dispensação de medicamentos, pois, visando suprir as possíveis omissões dos demais Poderes da República na efetivação do direito à saúde, o Judiciário passou a deferir os pedidos formulados nas ações judiciais. Apesar de teoricamente não ser o Judiciário a esfera adequada para a solução de conflitos envolvendo a alocação de recursos na área da saúde, o fato é que cada vez mais esse tipo de conflito, especialmente sobre o fornecimento de medicamentos, é levado à apreciação do Judiciário.

Assim, já que o Judiciário não poderá deixar de julgar, deverá apareIhar-se para melhor decidir conflitos dessa natureza. Na verdade, para superar os obstáculos a ele impostos, como visto acima, deverá este Poder buscar critérios para racionalizar e uniformizar sua atuação de forma a superar tais obstáculos.

Nesse sentido, o primeiro critério a ser adotado refere-se à verificação da padronização dos medicamentos pleiteados pelo Ministério da Saúde (46). Como já mencionado, atualmente são normas técnicas, em sua maioria Portarias, que regulamentam a assistência farmacêutica no SUS. Note-se que a fixação de obrigações subsidiárias pela Administração Pública por meio de normas infralegais está autorizada constitucionalmente (arts. 84, IV, e 87, parágrafo único, II), sendo um mecanismo de complementação das leis, indispensáveis à sua efetividade ${ }^{(47)}$. No caso da saúde, cabe ao respectivo Ministro expedir instruções para execução das leis, decretos e regulamentos nessa área e, no que se refere à política de medicamentos, sua formulação é atribuição do Departamento de Assistência Farmacêutica e Insumos Estratégicos - DAF(48).

(46) Recentes decisões dos Tribunais Superiores se referem à padronização de medicamentos. Citese, entre elas, no Supremo Tribunal Federal, a decisão na Suspensão de Tutela Antecipada n. 91, Relatora Ministra Ellen Gracie, tendo como requerente o Estado de Alagoas e requerido o Presidente do Tribunal de Justiça do Estado de Alagoas, publicada no Diário de Justiça de 05.03.2007 e, no Superior Tribunal de Justiça, a decisão no Agravo Regimental no Agravo Regimental na Suspensão de Tutela Antecipada n. 81-SC, 2004/0062451-9, Relator Ministro Edson Vidigal. Publicado no DJ de 29.08.2005.

(47) CARVALHO FILHO, José dos Santos. Manual de direito administrativo. 11. ed. Rio de Janeiro: Lumen Juris, 2004. p. 42.

(48) O DAF foi criado em junho de 2003 com a criação da Secretaria de Ciência e Tecnologia e Insumos Estratégicos (SCTIE), por meio do Decreto n. 4.726, de 9 de junho de 2003. Essa Secretaria incorporou as funções da extinta Secretaria de Políticas de Saúde, que realizava atividades no âmbito da atenção básica. A criação do DAF foi o primeiro passo para a institucionalização da Assistência Farmacêutica no Ministério da Saúde, com estrutura própria e a atribuição de formular e implementar a Política Nacional de Medicamentos e de Assistência Farmacêutica (Fonte: <http://portal.saude.gov.br/ portal/saude/visualizar_texto.cfm?idtxt=24318>). Sobre as atribuições do DAF consultar <http:// portal.saude.gov.br/portal/saude/visualizar_texto.cfm?idtxt=24386>. Acesso em: 10 jun. 2008. 
Com relação ao fornecimento de medicamentos, existe uma padronização elaborada pelo Ministério da Saúde, a qual comporta não somente produtos incluídos nos Programas de Assistência Farmacêutica deste órgão, mas produtos da Relação Nacional de Medicamentos Essenciais - RENAME(49), que em 2007, segundo o elenco elaborado por Pontes Junior ${ }^{(50)}$, comportava 427 fármacos.

Dessa forma, é indispensável que o Judiciário faça uso desta padronização ao decidir pedidos que versem sobre o fornecimento de medicamentos, verificando a adequação do medicamento pleiteado à lista de fármacos proposta pelo Ministério da Saúde. Eventualmente, nos casos em que as drogas pleiteadas não estiverem previstas na regulamentação sobre a matéria, o Judiciário deverá, então, cogitar de outros parâmetros, notadamente, a indispensabilidade do medicamento para a manutenção da vida do indivíduo e, adicionalmente, a opção pelo medicamento nacional, e, ainda, se possível, a opção pelo medicamento genérico, de menor custo e eficácia comprovada(51).

Destaque-se que o uso da padronização por si só já representa uma opção que incorpora uma série de outros critérios, pois o Poder Executivo por meio do DAF — ao adotar uma padronização de medicamentos pensou em critérios de seleção, tais como custo/benefício, dose/efetividade, risco/ benefício e efetividade/eficácia(52).

Adicionalmente, também mostra-se importante que o julgador verifique se o médico prescritor do medicamento e, desta forma, o receituário, fazem parte do Sistema Único de Saúde, de maneira a não se inverter a lógica do Sistema, privilegiando-se a compra de medicamentos a pacientes que não utilizaram as portas de entrada do SUS.

Tal critério justifica-se também porque a indústria farmacêutica exerce influência sobre os profissionais médicos ${ }^{(53)}$, principalmente sobre aqueles

(49) A Relação Nacional de Medicamentos Essenciais (Rename) é uma publicação elaborada pelo Ministério da Saúde, com base no quadro nosológico do país. Abrange um elenco de 330 fármacos, 08 correlatos e 34 imunoterápicos, em 522 apresentações. Disponível em: <http://portal.saude.gov.br/ portal/saude/area.cfm?id_area=1337>. Acesso em: 10 jun. 2008.

(50) PONTES JUNIOR, Durval Martins. A seleção de medicamentos para o monitoramento da qualidade laboratorial no Brasil: articulação entre a vigilância sanitária e a Política Nacional de Medicamentos. Rio de Janeiro, 2007. Dissertação (Mestrado) — Programa de Mestrado em Saúde Pública da Escola Nacional de Sáude Pública Sergio Arouca (ENSP)/FIOCRUZ. Disponível em: <http://www.ensp.fiocruz.br/visa/publicacoes/_arquivos/DissertacaoDurval.pdf>. Acesso em: 12 jul. 2007.

(51) Vide BARROSO. Da falta de efetividade à judicialização excessiva: direito à saúde, fornecimento gratuito de medicamentos e parâmetros para a atuação judicial. Disponível em <http:// conjur.estadao.com.br/pdf/estudobarroso.pdf>. Acesso em: 29 maio 2008.

(52) Nesse sentido ver MESSEDER, Ana Márcia; OSÓRIO-DE-CASTRO, SERPA, Claudia Garcia; LUIZA, Vera Lucia. Arcabouço legal da Política Nacional de Medicamentos no Brasil: uma revisão. In: GARCIA, Marcia et al. (Org.) Coleção Escola de Governo - Série Trabalhos de Alunos Vigilância em Saúde, Rio de Janeiro, 2004. v. 1, p. 25.

(53) TEMPORÃO, José Gomes. A propaganda de medicamentos e o mito da saúde. 1. ed. Rio de Janeiro: Graal, 1986. 
que trabalham em consultórios, por receberem com frequência propagandas de medicamentos distribuídas pelos visitadores de indústrias farmacêuticas, as quais, em sua grande parte, trazem informações pouco confiáveis, privilegiando benefícios em detrimento de riscos e omitindo ou alterando dados importantes sobre os fármacos ${ }^{(54)}$.

Além dos referidos critérios, faz-se necessário que se promova uma aproximação entre o Poder Judiciário e os órgãos do Poder Executivo responsáveis pela assistência farmacêutica e a dispensação de medicamentos. Em nível estadual, por exemplo, um maior diálogo entre as Secretarias de Saúde e os Tribunais Estaduais permitiria uma troca de informações sobre os medicamentos padronizados e aqueles objeto das demandas judiciais, o que poderia facilitar tanto a decisão das ações pelo Judiciário como a dispensação do medicamento pela Secretaria ${ }^{(55)}$.

Acrescente-se a isso uma conscientização dos médicos, prescritores dos medicamentos, também atores neste processo, seja no que se refere à padronização dos itens pelo Ministério da Saúde, seja no que toca à promoção do uso racional de medicamentos, aliás uma das diretrizes da Política Nacional de Medicamentos ${ }^{(56)}$.

Por fim, é importante destacar que a recente delegação de conflitos distributivos ao Judiciário pode funcionar como uma forma de potencializar conflitos sociais, que ganham força e podem passar a ser prioridade na agenda política do país. De fato, as demandas judiciais podem operar um efeito indutor no processo político, não só alterando as políticas públicas já em curso, mas indicando como devem ser pensadas políticas para o futuro. Nesse sentido, Alec Stone Sweet sustenta que

Concrete review referrals and individual complaints organize the protection of rights outside of parliamentary space. While designed to restore or protect individual rights that have already been violated, such procedures none the less have the capacity to generate or restructure ongoing and future legislative process. ${ }^{(57)(58)}$

Esse aspecto indutor das demandas judiciais pode ser ilustrado por meio da experiência canadense no chamado caso Chaoulli, julgado pela

(54) Sobre o tema, vide VEIRA, Rita de Cássia Padula Alves. Propagandas de medicamentos distribuídas aos médicos: aspectos legais, farmacológicos e de mercadização. Tese (Doutorado) Instituto de Medicina Social da Universidade do Estado do Rio de Janeiro, 2004.

(55) Cite-se, por exemplo, a realização de estudos estatísticos e o estabelecimento de convênios entre as Secretarias Estaduais e os Tribunais.

(56) A Política Nacional de Medicamentos foi aprovada pela Portaria n. 3.916/GM, de 30 de novembro de 1998.

(57) SWEET, Alec Stone. op. cit., p.113.

(58) Os requerimentos de inconstitucionalidade e os litígios judiciais individuais moldam a proteção de direitos fora da esfera parlamentar. Apesar de visarem a proteção de direitos já violados, tais procedimentos judiciais têm a capacidade de criar ou reestruturar futuros processos legislativos e os já em curso. Tradução livre das autoras. 
Suprema Corte do Canadá em 2005. Apesar das particularidades do sistema de saúde e do Judiciário canadenses, o caso, que se refere a uma ação judicial proposta por usuário do sistema público de saúde contra a província de Quebec pela longa espera para realização de cirurgia de joelho, provocou mudanças na legislação local, limitando o tempo em fila de espera para cirurgias eletivas ${ }^{(59)}$. Nesse sentido, como bem destaca Reinaldo Lima Lopes.

O Judiciário serve de alguma forma ainda para fazer justiça? Vale a pena mencionar pelo menos duas coisas: o fato do Judiciário converter-se numa arena de discussão em que as partes podem racionalizar seus interesses e sua concepção político-jurídica e o fato de que os bloqueios institucionais eventualmente criados por demandas judiciais têm a capacidade de explicitar conflitos sociais básicos da sociedade brasileira. O valor do Judiciário é garantir que os arranjos e disputas se façam sob a legalidade e dar visibilidade às diferentes reivindicações. Num sentido limitado, permite que o diálogo se estabeleça formalmente entre litigantes. ${ }^{(60)}$

Desta forma, deve o Judiciário servir também como veículo a ampliar a dimensão dos conflitos sociais em curso. No entanto, deve estar atento para que tais conflitos não se tornem uma busca individualizada pela efetivação de políticas públicas como vem ocorrendo no caso do fornecimento de medicamentos, pois dessa forma "a invasão da política pelo direito, mesmo que reclamada em nome da igualdade, levaria à perda da liberdade, 'ao gozo passivo de direitos', 'à privatização da cidadania' ao paternalismo estatal (...), 'à clericalização da burocracia', 'a uma justiça de salvação', com a redução dos cidadãos ao estatuto de indivíduos-clientes de um Estado providencial”'(61).

\section{REFERÊNCIAS BIBLIOGRÁFICAS}

AMARAL, Gustavo. Direito, escassez \& escolha: em busca de critérios jurídicos para lidar com a escassez de recursos e as decisões trágicas. Rio de Janeiro: Renovar, 2001.

AMATO NETO, Vicente; PASTERNAK, Jacyr. Sistemas de atendimento à saúde. Folha de S. Paulo, dia 11 jul. 2007. Disponível em: <http://si.knowtec.com: $8080 /$ scripts-si/MostraNoticia? \&idnoticia $=430175 \&$ idcontato $=1078 \&$ origem $=$ fiqueatento \&nomeCliente $=$ PROBRASI L\&data=2007-07-11>. Acesso em: 19 jun. 2008.

(59) Em resposta ao caso Chaoulli, o governo da província de Quebec procedeu a uma série de mudanças na sua legislação em fevereiro de 2006. A província mudou as leis locais para permitir a realização de três procedimentos eletivos, através do sistema de saúde privado, com pagamento pelo governo, quando as filas para realização de tais cirurgias ultrapassassem o prazo de nove meses. Tradução livre das autoras.

(60) LOPES, José Reinaldo de Lima. op. cit., p. 138.

(61) VIANNA, Luiz Jorge Werneck et al., op. cit., p. 23. 
BARROSO. Da falta de efetividade à judicialização excessiva: direito à saúde, fornecimento gratuito de medicamentos e parâmetros para a atuação judicial. Disponível em: <http://conjur.estadao.com.br/pdf/estudobarroso.pdf>. Acesso em: 29 maio 2008.

BOBBIO, Norberto. Dicionário de política. 5. ed. Brasília: Ed. da UnB; São Paulo: Imprensa Oficial do Estado de São Paulo, 2004. v. 1 e 2.

BORGES, Danielle da Costa Leite. Uma análise das ações judiciais para o fornecimento de medicamentos no âmbito do SUS: o caso do Estado do Rio de Janeiro no ano de 2005. Rio de Janeiro, 2007. Dissertação (Mestrado) Programa de Mestrado em Saúde Pública da Escola Nacional de Sáude Pública Sergio Arouca (ENSP)/FIOCRUZ. Disponível em: <http://bvssp.cict. fiocruz.br/lildbi/docsonline/3/3/1233-borgesdclm.pdf>. Acesso em: 26 maio 2008.

BRASIL. Constituição (1988). Constituição da República Federativa do Brasil: promulgada em 5 de outubro de 1988: atualizada até a Emenda Constitucional n. 42, de 19.12.2003. Rio de Janeiro: Lumen Juris.

Lei n. 8.080, de 19 de setembro de 1990. Dispõe sobre as condições para a promoção, proteção e recuperação da saúde, a organização e o funcionamento dos serviços e dá outras providências. DOU de 20 de setembro de 1990.

Lei n. 8.142, de 28 de dezembro de 1990. Dispõe sobre a participação na gestão do Sistema Único de Saúde (SUS) e sobre as transferências intergovernamentais de recursos financeiros na área da saúde e dá outras providências. DOU de 31 de dezembro de 1990.

MINISTÉRIO DA SAÚDE. Portaria n. 3.916/GM, de 30 de novembro de 1998. Aprova a Política Nacional de Medicamentos. DOU n. 215-E, Seção 1, p. 18 a 22, de 10 de novembro de 1998

MINISTÉRIO DA SAÚDE. Secretaria de Ciência Tecnologia e Insumos Estratégicos. Departamento de Assistência Farmacêutica e Insumos Estratégicos. Relação Nacional de Medicamentos Essenciais: RENAME, 2007. Disponível em: <http://bvsms.saude.gov.br/cgi-bin/wxis.exe/iah/ms/ ?\&lsisScript= iah\%2Fiah. xic\&lang= P\&base=MS\&nextAction=Ink\&exprSearch=RENAME $>$. Acesso em: 17 mar. 2007.

SENADO FEDERAL. Projeto de Lei do Senado n. 219/2007, de 03 de maio de 2007. Disponível em: <http://www.senado.gov.br/sf/atividade/ Materia/detalhes.asp?p_cod_mate=80822>. Acesso em: 10 jul. 2007.

SENADO FEDERAL. Projeto de Lei do Senado n.. 338/2007, de 13 de junho de 2007. Disponível em: <http://www.senado.gov.br/sf/atividade/ Materia/detalhes.asp?p_cod_mate=81517>. Acesso em: 10 jul. 2007. 
CANOTILHO, José Joaquim Gomes. Constituição dirigente e vinculação do legislador. 2. ed. Coimbra: Almedina, 2001.

CAPPELLETTI, Mauro. Juízes legisladores? Porto Alegre: Sérgio Fabris, 1999.

CARVALHO, Ernani Rodrigues de. Em busca da judicialização da política no Brasil: apontamentos para uma nova abordagem. Revista de Sociologia e Política, Curitiba, n. 23, p. 115-126, nov., 2004.

CARVALHO, Guido Ivan de; SANTOS, Lenir. Sistema Único de Saúde: Comentários à Lei Orgânica da Saúde (Leis 8.080/90 e 8.142/90). São Paulo: Hucitec, 1992.

CARVALHO FILHO, José dos Santos. Manual de direito administrativo. 11. ed. Rio de Janeiro: Lumen Juris, 2004.

CASTRO, Marcos Faro de. O Supremo Tribunal Federal e a judicialização da política. Revista Brasileira de Ciências Sociais, São Paulo, v. 12, n. 34, jul. 1997.

CONSELHO NACIONAL DE SECRETÁRIOS DE SAÚDE - CONASS. Assistência farmacêutica no SUS. 1. ed. Brasília: CONASS, 2007. (Coleção Progestores, v. 7).

CONSTANTINO, Luciana; FREITAS, Silvana. Saúde em xeque. Folha de $S$. Paulo, 01 ago. 2005. Disponível em: <http://sistemas.aids.gov.br/imprensa/ Noticias.asp?NOTCod=66473>. Acesso em: 19 jun. 2008.

DALLARI, Sueli Gandolfi. A justiça e o alto custo da saúde. In: DWORKIN, R. $A$ virtude soberana: a teoria e a prática da igualdade.1. ed. São Paulo: Martins Fontes, 2005.

Organização jurídica da Administração pública em saúde. In: RO-

ZENFELD, Suely (Org.). Fundamentos da vigilância sanitária. Rio de Janeiro: Fiocruz, 2000.

ESTEVES, João Luiz Martins. Cidadania e judicialização dos conflitos sociais. Revista Jurídica da Unifil, Londrina, v. 2, 2004.

FARIA, José Eduardo. Introdução: o Judiciário e o desenvolvimento sócio-econômico. In: FARIA, José Eduardo (Org.). Direitos humanos, direitos sociais e justiça. 1. ed. 4. tir. São Paulo: Malheiros Ed., 2005.

O Judiciário e os direitos sociais: notas para uma avaliação da justiça brasileira. In: FARIA, José Eduardo (Org.). Direitos humanos, direitos sociais e justiça. 1. ed. 4. tir. São Paulo: Malheiros Ed., 2005.

FERREIRA, Camila Duran et al. O Judiciário e as políticas de saúde no Brasil: o caso Aids. São Paulo, 2004. Monografia vencedora do Concurso de Monografias "Prêmio IPEA 40 anos". Disponível em: <http://getinternet.ipea.gov.br/Sobrelpea/40anos/estudantes/monografiacamila.doc>. Acesso em: 12 jan. 2008. 
GOUVÊA, Marcos Maselli. O direito ao fornecimento estatal de medicamentos. Revista de Direito da Associação dos Procuradores do Novo Estado do Rio de Janeiro, Rio de Janeiro, v. 12, p. 119-165, 2003.

GOVERNO DO ESTADO DO RIO DE JANEIRO. SECRETARIA DE ESTADO DE SAÚDE. Assessoria Técnica. Nota técnica sobre judicialização do acesso a medicamentos, de 17 de maio de 2006.

KOOPMANS, Tim. Courts and political institutions: a comparative view. Cambridge University Press, 2003.

LOPES, Claudia Rabelo; VASCONCELOS, Wagner. Quando o remédio pode virar veneno. Revista Radis - Comunicação em Saúde, n. 43, mar. 2006. Disponível em: <http://www.ensp.fiocruz.br/radis/43/pdf/radis_43.pdf>. Acesso em: 02 ago. 2006.

LOPES, José Reinaldo de Lima. Direitos sociais: teoria e prática. São Paulo: Método, 2006.

MACIEL, Débora Alves; KOERNER Andrei. Sentidos da judicialização da política: duas análises. Lua Nova - Revista de Cultura e Política/CEDEC. São Paulo, n. 57, p. 113-133, 2002.

MAGALHÃES, Sérgia Maria Starling; CARVALHO, Wania da Silva. O farmacêutico e o uso racional de medicamentos. In: ACURCIO, F. A. (Org.), Medicamentos e assistência farmacêutica. Belo Horizonte: Coopmed, 2003. p. 83-97.

MARCHILDON, Gregory P. Managerial versus financial reform and the future of public health care in Canadá. Eurohealth, v. 12, n. 1, p. 23-25, 2006.

MESSEDER, Ana Márcia; OSÓRIO-DE-CASTRO, SERPA, Claudia Garcia; LUIZA, Vera Lucia. Arcabouço legal da Política Nacional de Medicamentos no Brasil: uma revisão. In: GARCIA, Marcia et al. (Org.) Coleção Escola de Governo - Série Trabalhos de Alunos -Vigilância em Saúde, Rio de Janeiro, 2004. v. 1, p. 13-41.

Mandados judiciais como ferramentas para garantia do acesso a medicamentos no setor público: A experiência do Estado do Rio de Janeiro, Brasil. Cadernos de Saúde Pública, Rio de Janeiro, v. 21, n. 2, p. 525-534, mar./abr. 2005.

MINISTÉRIO DA SAÚDE. SECRETARIA DE CIÊNCIA, TECNOLOGIA E INSUMOS ESTRATÉGICOS. DEPARTAMENTO DE ASSISTÊNCIA FARMACÊUTICA E INSUMOS ESTRATÉGICOS. A Organização dos Serviços de Assistência Farmacêutica no Sistema Único de Saúde. Disponível em: <http://portal.saude.gov.br/ portal/arquivos/pdf/a_organizacao_dos_servicos\%20de_daf.pdf>. Acesso em: 11 jun. 2008.

MORAES, Alexandre de. Direito constitucional. 11. ed. São Paulo: Atlas, 2002. 
MOREIRA NETO, Diogo de Figueiredo. Agências Reguladoras (descentralização e deslegalização. In: MOREIRA NETO, Diogo de Figueiredo. Mutações do direito administrativo. 2. ed. Rio de Janeiro: Renovar, 2001.

PONTES JUNIOR, Durval Martins. A seleção de medicamentos para o monitoramento da qualidade laboratorial no Brasil: articulação entre a vigilância sanitária e a Política Nacional de Medicamentos. Rio de Janeiro, 2007. Dissertação (Mestrado) - Programa de Mestrado em Saúde Pública da Escola Nacional de Sáude Pública Sergio Arouca (ENSP)/FIOCRUZ. Disponível em: <http:// www.ensp.fiocruz.br/visa/publicacoes/_arquivos/DissertacaoDurval.pdf>. Acesso em: 12 jul. 2007.

SANTOS, Lenir. SUS: contornos jurídicos da integralidade da atenção à saúde. Revista do Conselho Nacional de Secretarias Municipais de Saúde CONASEMS, Brasília, ano 2, n. 19, p. 46-47, set./out. 2006.

SHAPIRO, Martin; SWEET, Alec Stone. On law, politics and judicialization. Oxford: Oxford University Press, 2002.

SILVA, José Afonso da. Aplicabilidade das normas constitucionais. 2. ed. São Paulo: Ed. Revista dos Tribunais, 1982.

SILVA, José Afonso da. Curso de direito constitucional positivo. 9. ed. rev. 3. tir. São Paulo: Malheiros Ed., 1993.

SWEET, Alec Stone. Governing with judges: constitutional politics in Europe. Oxford: Oxford University Press, 2000.

TATE, C. Neal. Why the expansion of Judicial Power. In: TATE, C. Neal; VALLINDER, Torbjörn. The global expansion of Judicial Power. New York: New York University Press, 1995.

TATE, C. Neal; VALLINDER, Torbjörn. Judicialization and the future of politics and policy. In: TATE, C. Neal; VALLINDER, Torbjörn. The global expansion of Judicial Power. New York: New York University Press, 1995.

The global expansion of Judicial Power. New York: New York University Press, 1995.

TAYLOR, Matthew. M. Citizens against the State: the riddle of high impact, low functionality courts in Brazil. Brazilian Journal of Political Economy, v. 25, n. 4, fasc. 100, p. 418-438, Oct./Dec. 2005.

TEIXEIRA, Ariosto. A judicialização da política no Brasil (1990-1996). Dissertação (Mestrado) - Universidade de Brasília - UnB, Brasília, 1997. Mimeo.

TEMPORÃO, José Gomes. A propaganda de medicamentos e o mito da saúde. 1. ed. Rio de Janeiro: Graal, 1986.

TORRES, Ricardo Lobo. A cidadania multidimensional na era dos direitos. In: TORRES, Ricardo Lobo. Teoria dos direitos fundamentais. 2. ed. rev. e atual. Rio de Janeiro: Renovar, 2001. 
VALLINDER, Torbjörn. When courts go marching. In: TATE, C. Neal; VALLINDER, Torbjörn. The global expansion of Judicial Power. New York: New York University Press, 1995.

VEIRA, Rita de Cássia Padula Alves. Propagandas de medicamentos distribuídas aos médicos: aspectos legais, farmacológicos e de mercadização. Tese (Doutorado) - Instituto de Medicina Social da Universidade do Estado do Rio de Janeiro, 2004.

VIANNA, Luiz Jorge Werneck et al. A judicialização da política e das relações sociais no Brasil. Rio de Janeiro: Revan, 1999.

; BURGOS, Marcelo Baumann; SALLES, Paula Martins. Dezessete anos de judicialização da política. Tempo Social: revista de sociologia da USP, São Paulo, v. 19, n. 2, p. 39-85. 